\title{
Conflict-related violence and mental health among self-settled Democratic Republic of Congo female refugees in Kampala, Uganda - a respondent driven sampling survey
}

Itziar Familiar ${ }^{1}$, Pamela Nasirumbi Muniina ${ }^{2}$, Chris Dolan ${ }^{3}$, Moses Ogwal ${ }^{4}$, David Serwadda ${ }^{5}$, Herbert Kiyingi ${ }^{2}$, Chantal Siya Bahinduka ${ }^{6}$, Enos Sande ${ }^{2}$ and Wolfgang Hladik ${ }^{7^{*}}$ (D)

\begin{abstract}
Background: Violence and traumatic events are highly prevalent among refugees, but less is known about the impact of these experiences among self-settled refugees in the country of asylum. We evaluated the association between traumatic experiences and PTSD and depression symptoms among female Democratic Republic of Congo (DRC) refugees living in Kampala, Uganda.

Methods: Participants were recruited using respondent driven sampling in one refugee service center in Kampala, Uganda. Eligibility criteria included: Congolese nationality, age 18+ years, self-settled in Kampala for at least 6 months, refugee status or documentation of application for refugee status. Only data from female participants were included in this analysis. Depression symptoms were screened with the Patient Health Questionnaire-2, and symptom criteria for PTSD and traumatic experiences were evaluated with the Harvard Trauma Questionnaire. Logistic regression models were performed to separately assess associations between mental health outcomes (PTSD and depression), rape and non-sexual violence.
\end{abstract}

Results: Five hundred eighty women with a mean age of 33 years were interviewed. Among participants, $73 \%$ (95\% Cl:67-78\%) met symptom criteria for PTSD, 57\% (95\% Cl: 51-63\%) for depression, and 65\% reported thoughts of ending one's life. 79\% of women reported experience of rape, for over half (54\%) it occurred more than once, and $82 \%$ were gang raped. Crude and adjusted odds ratios (ORs) show that PTSD was most strongly associated with being raped $(\mathrm{OR}=2.43, p<0.01)$, lacking shelter $(\mathrm{OR}=2.86, p<0.01)$, lacking food or water $(\mathrm{OR}=2.53, p=$ $0.02)$, lacking access to health care $(\mathrm{OR}=2.84, p<0.01)$, forced labor $(\mathrm{OR}=2.6, p<0.01)$, extortion and/or robbery $(\mathrm{OR}=3.08, p<0.01)$, experiencing the disappearance/kidnapping of a family member or friend $(\mathrm{OR}=2.72, p<0.01)$, and witnessing the killing or murder of other people $(\mathrm{OR}=3.28, p<0.01)$. Depression was significantly associated with several traumatic experiences including rape $(\mathrm{OR}=2.3, p=0.01)$, and experiencing the disappearance/

\footnotetext{
* Correspondence: wfh3@cdc.gov

${ }^{7}$ Division of Global HIV and TB, Centers for Disease Control and Prevention, MS E-30, 1600 Clifton Rd, Atlanta GA-30333, USA

Full list of author information is available at the end of the article
} changes were made. The images or other third party material in this article are included in the article's Creative Commons licence, unless indicated otherwise in a credit line to the material. If material is not included in the article's Creative Commons licence and your intended use is not permitted by statutory regulation or exceeds the permitted use, you will need to obtain permission directly from the copyright holder. To view a copy of this licence, visit http://creativecommons.org/licenses/by/4.0/ The Creative Commons Public Domain Dedication waiver (http://creativecommons.org/publicdomain/zero/1.0/) applies to the data made available in this article, unless otherwise stated in a credit line to the data. 
kidnapping of a child or spouse ( $O R=1.99, p=0.01)$.

Conclusions: Refugee women self-settled in Kampala reported high lifetime experiences of violence and traumatic events including rape, as well as high rates of PTSD and depression. Future programming addressing self-settled refugees and their settlement in host countries may benefit from including local and national integration strategies.

Keywords: DR Congo, Uganda, Refugees, Female, Rape, Mental health

\section{Background}

Since the first and second Congo Wars in 1996-1997 and 1998-2003, respectively, political instability and armed conflict has forced an estimated 4.5 million people to flee from the Democratic Republic of Congo (DRC). The UN High Commissioner for Refugees [1] estimated that as of February 2019, over 826,000 DRC refugees were being hosted in African countries, with as many as $60 \%$ of them currently living in Uganda [2]. The multiple armed conflicts affecting DRC's vast territory make this one of the most challenging humanitarian emergencies of our time. A tragic feature of the armed conflict in the DRC has been the use of widespread sexual violence against women, including rape, as a tactic of war and destabilization [3].

The events leading to forced migration, as well as flight itself and life in the country of asylum, are frequently accompanied by exposure to an array of traumatic events such as severe physical and sexual violence, death threats, witnessing family and others being killed, kidnapped, or abused [4]. These events can be emotionally shocking, and rates of stress and mental health disorders, such as anxiety disorders, post-traumatic stress disorder (PTSD), and depression are higher among refugees than in the general population [5].

Women are more frequently victims of sexual violence and the prevalence of PTSD and poor mental health after rape is particularly high. A systematic review and meta-analysis estimated the prevalence of sexual violence and rape among female refugees and those internally displaced at $21 \%$ (CI 95\% 14.9-28.7) [6], with authors warning about the potential underestimation due to barriers in reporting. In the DRC, population-based studies show that more than $40 \%$ of women have experienced sexual violence including rape $[7,8]$ and upwards of $50 \%$ among female refugees [9]. Studies of DR Congolese civilians and refugees have found higher prevalence of PTSD, depression, suicidal ideation, and suicidal attempts among women who have experienced sexual violence $[7,10]$.

Most studies describing mental health issues of refugees are based on reports from individuals assessed within organized temporary settlements. Less is known about the considerable large number of refugees who have chosen to 'self-settle' within a host population. Self-settled and urban refugees may be more vulnerable to exploitation, persecution and arrest, given that although they are recognized as refugees, there is little in the way of practical assistance or protection to those living outside gazetted refugee settlements [2]. Ensuring support and access to basic services for individuals concealed in the anonymity of a city can be challenging, increasing the likelihood of risk-taking behaviors, and negative health outcomes [1]. Self-settled refugees may experience higher levels of violence and rape with even less support available than what refugees in camps may have access to from medical non-governmental organizations (NGOs). Determining the type and magnitude of mental health problems urban refugees experience is crucial to plan and deliver adequate services, and requires methods that can be used to generate valid estimates for hidden populations that do not have a sampling frame.

The purpose of this study was to investigate rates of PTSD and depression symptoms in a population of female DR Congolese refugees living in Kampala, Uganda and their association with traumatic experiences including rape, to inform policy and service provision in host countries.

\section{Methods}

Data come from the Crane Survey, a cross-sectional survey conducted in Kampala, Uganda between July 25th and November 29th, 2013 by the Crane Survey of Makerere University School of Public Health, the US Centers for Disease Control and Prevention, and the Refugee Law Project.

\section{Participant recruitment}

Study participants were recruited using respondentdriven sampling (RDS), a peer-to-peer recruitment approach used to sample hard-to-reach populations where no sampling frame is available. A single survey office located in a dense urban area near the city center was used as the survey site. Survey participation involved two visits to the survey office. In the first visit, the coupon received by one of two seeds was validated, and candidate participants were screened in a face-to-face interview for eligibility (DR Congolese nationality, age 18+ years, self-settled in Kampala for at least 6 months, self- 
reported refugee status or documentation of application for refugee status). If eligible, and after providing informed consent, participants were interviewed and offered testing for syphilis and HIV. A second visit was scheduled 2 weeks later, to return test results, administer a short peer recruitment interview and provide compensation for transport and participation as detailed below.

\section{Procedure}

\section{Instruments}

All instruments were translated into Swahili and French and back translated by local research assistants. To increase confidentiality and data protection, survey instruments were administered to participants using an audio computer-assisted self-interview (ACASI) in a password protected tablet using Questionnaire Design Studio (Nova Research). Research staff introduced the ACASI format to participants through a tutorial and then left the participant to provide privacy but remained within sight or earshot to troubleshoot as needed. ACASI accommodates low and illiterate respondents. The few participants who were overwhelmed by the computer setting were offered a computer-assisted personal interview. Data were entered and merged in a password protected study laptop only accessed by authorized study personnel and de-identified before analyses.

To estimate the personal network size, participants were asked "How many [self-settled DR Congolese refugees] do you know by sight or name?", continuing with the following probes: "Of these, how many live in Kampala?", "How many are aged 18 or older", and "Of these, how many could you give a survey coupon by this time next week?". Throughout the survey procedures, Congolese survey volunteers helped with communication and explanations as needed, in addition to the main Ugandan survey staff.

Mental health outcomes were assessed using questionnaires previously administered in refugee settings. The validated short form of the Patient Health Questionnaire-2 (PHQ-2) [11] was used to screen for depressive symptomatology. The PHQ-2 inquires on the frequency of anhedonia and depressed mood in the past 2 weeks. Scores range from 0 to 6 and the established cut-off value of 3 was used to denote probable depression. Finally, one binary (yes/no) question asked about thoughts of ending one's own life.

PTSD was assessed with the first 16 trauma symptom items of the Harvard Trauma Questionnaire (HTQ), derived from the DSM-IV PTSD criteria [12]. Respondents endorsed how much each symptom bothered them in the past week using a four-point Likert scale (not at all, several days, more than half the days, nearly every day). The HTQ-PTSD score is an average score, with a cut-off score of 2.5 used to suggest that the respondent has a high likelihood of clinically meaningful PTSD. Cronbach's alpha for the HTQ-PTSD was 0.85. Part I of the HTQ (46 item version) was used and adapted to inquire about traumatic events experienced before fleeing, including physical and sexual violence. Rape was defined answering yes to the HTQ item ("Have you experienced rape") and follow up questions to positive responses were added to collect additional data including, gang rape (defined as two or more persons involved in the rape incident), number of incidents, time of rape (before, during or after displacement), location, perpetrator, injuries sustained, report to authorities, and services received. Social support was measured through the Multidimensional Scale of Perceived Social Support (MSPSS) [13], a brief research tool designed to measure perceptions of social support from three sources; family, friends and a significant other. The scale is comprised of 12 items answered with a 7-point Likert scale, which in this survey were collapsed into a five-point Likert scale ( 1 = strongly disagree, $2=$ mildly disagree, $3=$ neutral, $4=$ mildly agree, $5=$ strongly agree) to accommodate the ACASI formatting ('very strongly disagree' and 'very strongly agree were' eliminated). Following standard scoring and cut-off guidance [13], a total mean score was calculated, with any mean total scale score ranging from 1 to 2.9 considered low support, a score of 3-5 considered moderate support, and a score $>5.1$ considered as high support. Cronbach alpha for the MSPSS was 0.9 .

\section{Ethical considerations}

All participants provided oral informed consent for their participation in the survey and testing. No personal identifiers were recorded. Participants who tested positive for syphilis were offered treatment at the survey site according to the Ugandan Ministry and World Health Organization guidelines. Participants who tested HIVpositive received a referral letter for a provider of their choice in Kampala. Self-administered interview responses in ACASI were not reviewed in real time. However, high response values (i.e. Likert response of 4 or "Extreme") to specific HTQ items were flagged (recurrent thoughts or memories of most terrifying events, recurring nightmares, unable to feel emotions), as well as "thoughts of harming oneself", and alerted study staff to talk with the participant and offer referrals to counseling services at Refugee Law Project. Participants who expressed suicidal ideation during interview, or at any other survey stage were counseled and given a mental health-related referral to Butabika National Referral Hospital. Compensation for participants' time, transport and peer-referral efforts amounted to \$5.2 USD for their first survey visit and \$5.4 USD for the return visit (for an average of successfully referring 1.5 recruits). The survey 
protocol was approved by the ethics committee of Makerere University's School of Public Health and the Uganda National Council of Science and Technology and was reviewed by CDC's Associate Director of Science. This project was also reviewed in accordance with the Centers for Disease Control and Prevention (CDC) human research protection procedures and was determined to be research, but CDC investigators did not interact with human subjects or have access to identifiable data or specimens for research purposes.

\section{Statistical analysis}

Analysis of recruitment patterns and potential biases was done with RDS-Analyst [14]. Estimates were adjusted to account for the non-random sampling using RDS-Analyst population proportion weighting generated from the mean network size. All further data analysis was done using STATA 11 [15]. Key demographics, violence, and mental health outcomes were summarized and reported as mean $+-\mathrm{SD}$ or proportion. Unadjusted and adjusted regression models were performed to separately assess associations between mental health outcomes (a continuous PTSD score and dichotomous depression variable) and sexual (e.g. rape) and nonsexual violence reported. Adjusted analyses included variables with a significant association (i.e. $p<0.05$ ) in bivariate analyses with outcomes (age, educational status, marital status, and level of social support) (results not shown). Odds ratios (OR) were used to estimate risk and 95\% CI for crude and multivariate models. All tests were two-sided and $p<0.05$ was considered significant.

\section{Results}

Research assistants in conversation with investigators purposefully selected and recruited two seeds who selfreported large personal network sizes. Seed participants were initially given three coupons per recruit. A total of 1560 participants were initially assessed, of which 223 did not meet the full inclusion criteria and were not included. Total coupon uptake was 0.76 (1560 redeemed/ 2051 issued). In total, 1337 participants were eligible and completed the first visit, of which 580 were women and were included in this analysis.

Women were on average 33.7 years of age, $42 \%$ had completed between 8 and 12 years of schooling, and the majority (66\%) were from the North Kivu province in DRC. Seventy-eight percent had been residing in Uganda less than 6 years and $23 \%$ had been in a refugee camp before settling in Kampala. At the time of the survey, women reported being mostly married (42\%), unemployed (43\%), and living with family (79\%) (Table 1).

Among participants, 73\% (95\% CI: 67-78\%) met symptom criteria for PTSD, 57\% (95\% CI: $51-63 \%$ ) for depression, and $65 \%$ reported thoughts of ending one's life.
Two-thirds of women reported high social support levels (62\% for the total score, $66 \%$ for family support, $66 \%$ for support from friends, and $66 \%$ from significant others).

Eighty percent of women reported having been raped and over half $(55 \%)$ reported more than one rape incident. Of those raped, the majority of women reported being gang raped $(82 \%)$, with $39 \%$ of gang-rape victims reporting more than 4 perpetrators involved at a time. $61 \%$ of women described the rape occurring before displacement and $50 \%$ identified the police or government soldiers as perpetrators. Consequences of rape included, $87 \%$ reported genital injuries, $18 \%$ developed a fistula, and $26 \%$ resulted in pregnancies (Table 2). $47 \%$ of women declared reporting the rape incident to authorities, and 57\% received some type of health care.

Non-sexual traumatic incidents reported included experiencing a combat situation (93\%), lack of food or water $(88 \%)$, destruction of property $(84 \%)$, physical abuse $(84 \%)$, forced separation from family $(84 \%)$, lack of shelter $(83 \%)$, lack of access to health care $(79 \%)$, extortion or robbery $(78 \%)$, and witnessing beatings/torture (74\%) (Table 3).

Crude and adjusted ORs show that PTSD was most strongly associated with being raped $(\mathrm{OR}=2.43, p<$ $0.01)$, being raped after displacement $(\mathrm{OR}=3.17, p<$ $0.001)$, lacking shelter $(\mathrm{OR}=2.86, p<0.01)$, lacking food or water $(\mathrm{OR}=2.53, p=0.02)$, lacking access to health care $(\mathrm{OR}=2.84, p<0.01)$, forced labor $(\mathrm{OR}=2.6, p<$ $0.01)$ extortion and/or robbery $(\mathrm{OR}=3.08, p<0.01)$, experiencing the disappearance/kidnapping of a family member or friend $(\mathrm{OR}=2.72, p<0.01)$, and witnessing the killing or murder of other people $(\mathrm{OR}=3.28, p<$ 0.01) (Table 4). Number of traumatic experiences reported had a dose-response relationship with PTSD; women reporting at least 11 different incidents and above 15 had higher odds of PTSD (OR $=1.21$, CI 95\% $1.12-1.29, p<0.001$; OR $=2.15$, CI 95\% 1.42-3.24, $p<$ 0.001 , respectively) than those reporting 10 or fewer.

In adjusted models, depression was significantly associated with several traumatic experiences including rape $(\mathrm{OR}=2.3, p=0.01)$, and experiencing the disappearance/kidnapping of a child or spouse (OR $=1.99, p=$ 0.01) (Table 5).

\section{Discussion}

This is one of the few studies, to our knowledge, utilizing ACASI methodology to describe mental health outcomes among Congolese female refugees living in an urban environment. Among those interviewed, we found that women reported high rates of rape, and that this was associated with higher levels of PTSD and depression. Results highlight important mental and physical health needs of refugee women who, under their host country's refugee assistance policies, are largely excluded 
Table 1 Demographic characteristics of Congolese women living in Kampala, Uganda

\begin{tabular}{|c|c|c|}
\hline Characteristic & $\begin{array}{l}\text { Value } \\
(n=580)\end{array}$ & $\begin{array}{l}\text { Weighted } \\
\text { percentage }(95 \% \mathrm{Cl})\end{array}$ \\
\hline \multicolumn{3}{|l|}{ Age } \\
\hline $18-24$ & 121 & $20.3(16.1-25.3)$ \\
\hline $25-34$ & 210 & $37.1(31.5-43.1)$ \\
\hline $35+$ & 249 & $42.6(36.7-48.8)$ \\
\hline Mean age & & $33.7(32.3-35.0)$ \\
\hline \multicolumn{3}{|l|}{ Residence in DRC (Province) } \\
\hline North Kivu & 354 & $65.8(59.2-71.8)$ \\
\hline South Kivu & 153 & $31.2(25.3-37.7)$ \\
\hline Other & 17 & $3.1(1.4-6.4)$ \\
\hline \multicolumn{3}{|l|}{ Duration of residence in Uganda } \\
\hline $1-5$ years & 442 & $78.1(73.1-82.4)$ \\
\hline $6-10$ years & 115 & $19.4(15.3-24.4)$ \\
\hline$>10$ years & 23 & $2.5(1.4-4.2)$ \\
\hline Mean duration & & $4.1(3.8-4.4)$ \\
\hline \multicolumn{3}{|l|}{ Education (Years in school) } \\
\hline No school & 42 & $10.2(6.8-15.0)$ \\
\hline Primary (1-7 years) & 189 & $35.9(30.3-42.0)$ \\
\hline Secondary (8-12 years) & 269 & $41.8(36.1-47.9)$ \\
\hline Higher education (13+ years) & 80 & $12.0(8.6-16.5)$ \\
\hline Mean years in school & & $8.2(7.6-8.7)$ \\
\hline \multicolumn{3}{|l|}{ Marital status } \\
\hline Never married & 175 & $27.2(22.4-32.6)$ \\
\hline Married & 222 & $42.5(36.6-48.7)$ \\
\hline Divorced/Separated & 81 & $12.8(8.3-19.6)$ \\
\hline Widowed & 102 & $17.5(13.0-23.0)$ \\
\hline Lives with family & 485 & $79.5(73.7-84.3)$ \\
\hline \multicolumn{3}{|l|}{ Current work } \\
\hline Manual labor & 227 & $34.0(28.6-39.9)$ \\
\hline Skilled labor & 24 & $5.3(2.9-9.6)$ \\
\hline Study & 14 & $3.0(1.4-6.3)$ \\
\hline Unemployed & 227 & $42.7(36.7-48.8)$ \\
\hline Other & 88 & $15.1(11.3-19.7)$ \\
\hline Currently employed (Yes) & 339 & $54.4(42.9-69.2)$ \\
\hline $\begin{array}{l}\text { Lived in a refugee camp before } \\
\text { living in Kampala }\end{array}$ & 109 & $22.8(17.9-28.4)$ \\
\hline \multicolumn{3}{|l|}{ Source of refugee assistance/support } \\
\hline Refugee Law Project & 132 & $20.6(16.3-25.6)$ \\
\hline Interaid & 362 & $59.0(52.9-64.9)$ \\
\hline UNHCR & 155 & $23.8(19.3-29.1)$ \\
\hline At least one & 478 & $80.4(85.0-74.8)$ \\
\hline None & 102 & $19.6(15.0-25.2)$ \\
\hline
\end{tabular}

Table 2 Sexual violence reported by Congolese women living in Kampala, Uganda

\begin{tabular}{|c|c|c|}
\hline Characteristic & $\begin{array}{l}\text { Value }(n= \\
580)\end{array}$ & $\begin{array}{l}\text { Weighted percentage } \\
(95 \% \mathrm{Cl})\end{array}$ \\
\hline Raped & 454 & $79.5(74.3-83.9)$ \\
\hline \multicolumn{3}{|l|}{ No. rape incidents } \\
\hline Once & 210 & $45.5(38.8-52.4)$ \\
\hline More than once & 244 & $54.5(47.6-61.2)$ \\
\hline \multicolumn{3}{|l|}{ Time of rape } \\
\hline Before displacement & 285 & $61.0(54.1-67.5)$ \\
\hline During displacement & 153 & $35.4(29.1-42.3)$ \\
\hline After displacement & 104 & $20.6(15.7-26.5)$ \\
\hline \multicolumn{3}{|l|}{ Place where rape occurred } \\
\hline DRC & 404 & $89.4(84.3-93.0)$ \\
\hline Uganda & 108 & $19.4(14.9-24.8)$ \\
\hline Other & 14 & $3.4(1.8-6.4)$ \\
\hline \multicolumn{3}{|l|}{ Rape perpetrator } \\
\hline Militia & 108 & $23.5(18.1-30.0)$ \\
\hline Police/ Government solders & 247 & $50.5(43.6-57.3)$ \\
\hline UN/ NGO staff & 41 & $11.1(7.3-16.5)$ \\
\hline $\begin{array}{l}\text { Other (neighbor, relative, } \\
\text { stranger) }\end{array}$ & 110 & $23.6(18.5-29.7)$ \\
\hline Gang raped (Yes) & 371 & $81.7(75.8-86.4)$ \\
\hline \multicolumn{3}{|l|}{ Gang rape frequency $(N=371)$} \\
\hline Once & 196 & $55.0(47.3-62.4)$ \\
\hline More than once & 175 & $45.0(35.9-55.8)$ \\
\hline Mean & & $2.4(1.8-3.0)$ \\
\hline \multicolumn{3}{|l|}{ No. of gang rape perpetrators } \\
\hline$<4$ & 211 & $61.4(53.9-68.5)$ \\
\hline $4+$ & 160 & $38.6(31.5-46.1)$ \\
\hline Mean & & $4.5(3.7-5.3)$ \\
\hline Raped with an object & 213 & $46.0(39.3-52.8)$ \\
\hline $\begin{array}{l}\text { Received health care for rape } \\
\text { injuries }\end{array}$ & 263 & $57.5(50.6-64.1)$ \\
\hline $\begin{array}{l}\text { Received HIV post exposure } \\
\text { prophylaxis }\end{array}$ & 195 & $45.7(38.9-52.6)$ \\
\hline Reported rape to authorities & 226 & $47.3(40.5-54.1)$ \\
\hline Sustained genital injuries & 393 & $86.7(81.8-90.4)$ \\
\hline Fistula as a result of rape & 60 & $18.3(13.1-24.9)$ \\
\hline Pregnancy as result of rape & 132 & $26.2(20.7-32.5)$ \\
\hline
\end{tabular}

from direct assistance, whether in terms of access to health care or psychosocial support.

The finding that almost $80 \%$ of women had experienced rape and that, of those who reported rape, more than half (54\%) had experienced more than one incident of rape, underscores the serious threat that women refugees face. The fact that $20 \%$ of respondents reported being raped in the country of asylum and that higher rates 
Table 3 Other trauma reported by Congolese women living in Kampala, Uganda

\begin{tabular}{|c|c|c|}
\hline Characteristic & $\begin{array}{l}\text { Value } \\
(n=580)\end{array}$ & $\begin{array}{l}\text { Weighted } \\
\text { percentage }(95 \% \\
\text { Cl) }\end{array}$ \\
\hline Lack of shelter & 492 & $82.7(77.5-86.9)$ \\
\hline Lack of food or water & 511 & $87.9(83.2-91.4)$ \\
\hline Lack of access to health care & 453 & $79.2(74.1-83.5)$ \\
\hline Destruction of property & 505 & $84.3(79.1-88.4)$ \\
\hline Experience of combat situation & 527 & $92.7(89.3-95.1)$ \\
\hline Physical abuse & 473 & $84.2(79.8-87.7)$ \\
\hline Knifing & 224 & $37.6(32.0-43.7)$ \\
\hline Torture & 356 & $60.9(54.8-66.7)$ \\
\hline War-related injury & 306 & $54.0(47.9-60.0)$ \\
\hline Imprisonment & 106 & $18.1(13.9-23.1)$ \\
\hline Forced labor & 244 & $43.5(37.6-49.6)$ \\
\hline Extortion & 467 & $77.9(72.4-82.7)$ \\
\hline Kidnapped & 314 & $55.1(49.0-61.0)$ \\
\hline Forced separation from family & 492 & $84.1(79.5-87.8)$ \\
\hline Forced to find and bury bodies & 161 & $27.8(22.7-33.5)$ \\
\hline Prevented from burying someone & 163 & $29.5(24.3-35.4)$ \\
\hline Forced to desecrate bodies or graves & 33 & $6.4(4.0-10.3)$ \\
\hline $\begin{array}{l}\text { Forced to physically harm another } \\
\text { person }\end{array}$ & 90 & $18.3(13.9-23.7)$ \\
\hline Forced to betray family or friend & 39 & $10.0(6.5-15.1)$ \\
\hline $\begin{array}{l}\text { Experienced violent death of spouse } \\
\text { or child }\end{array}$ & 192 & $32.9(27.4-38.9)$ \\
\hline $\begin{array}{l}\text { Experienced other family member or } \\
\text { friend's violent death }\end{array}$ & 228 & $39.8(34.0-45.9)$ \\
\hline $\begin{array}{l}\text { Experienced disappearance, } \\
\text { kidnapping of spouse or child }\end{array}$ & 285 & $48.5(42.5-54.6)$ \\
\hline $\begin{array}{l}\text { Experienced disappearance, } \\
\text { kidnapping of family or friend }\end{array}$ & 281 & $42.0(36.2-48.0)$ \\
\hline $\begin{array}{l}\text { Witness physical injury of family or } \\
\text { friend }\end{array}$ & 319 & $58.0(52.0-63.8)$ \\
\hline Witnessed beating/torture & 424 & $74.0(68.2-79.1)$ \\
\hline Witnessed killings or murders & 294 & $49.9(43.8-56.0)$ \\
\hline \multicolumn{3}{|l|}{ Number of traumatic experiences } \\
\hline$<=10$ traumatic experiences & 133 & $21.8(17.3-27.0)$ \\
\hline $\begin{array}{l}\text { Between } 11 \text { and } 15 \text { traumatic } \\
\text { experiences }\end{array}$ & 255 & $43.9(37.9-50.0)$ \\
\hline$>15$ traumatic experiences & 192 & $34.3(28.8-40.4)$ \\
\hline
\end{tabular}

of PTSD were associated with being raped postdisplacements points to serious gaps in the protection afforded to self-settled refugees. Rates of sexual violence in this sample were higher than in similar studies; among adult women fleeing conflict in Liberia (60\%), among women living in DRC (16\%) [16], and in a previous study of Congolese refugees living in Kampala [10]. The discrepancy in prevalence rates may be the result of several factors, including different populations assessed or differences in the survey tools used. For example, we found higher rates of sexual violence than those reported by Morof and colleagues (2014), who also used RDS methodology to sample hard-to-reach women refugees living in Kampala. This difference could be the result of combining RDS with survey techniques that enable participants to privately answer sensitive questions (ACAS I). As in other studies, rape was most frequently perpetrated at the hands of armed groups and often combined with additional traumatic experiences such as destruction of property, forced labor, death of family and kidnappings [17].

Although rape may have been a driver of displacement (60\% reported being raped before displacement), more than one third (35\%) of women reported being raped in transit, and $20 \%$ in the host country. Local policy and services directed to refugees need to recognize that the current practice of providing support primarily to settlement-based refugees in rural areas fails to recognize the multiple needs and safety concerns of women refugees living in urban areas.

Depending on the population sampled, between 30 and $70 \%$ of refugees screen positive for PTSD $[5,18]$, with variations mostly accounted for by population characteristics and survey tools used. Rate of PTSD (73\%) based on symptom criteria in this study was higher than that of Congolese women in other studies [7, 10, 19], suggesting the higher need to understand and respond to mental health needs of self-settled refugees. PTSD symptom severity among refugees has been linked to poor executive functioning [9], possibly compromising their psychosocial functioning and ability to navigate complex postmigration environments. As in previous reports among women refugees [10, 20], likelihood of PTSD and depression was greater for women reporting rape and other warrelated exposures years after their initial arrival to the host country, even after adjusting for age and sociodemographic factors. The potential for long-lasting symptoms after sexual violence and rape has been described in the Rape Trauma Syndrome (RTS) [21], a nomenclature used to describe post-traumatic stress symptoms that arise from sexual assault not usually diagnosed in PTSD, including sexual dysfunction, long-term depression, fear, anxiety, social maladjustment, and humiliation [22].

Importantly, we found that odds of PTSD were also high among women reporting non-violent experiences such as lacking shelter ( $\mathrm{OR}=2.86, p<0.01)$, lacking food or water $(\mathrm{OR}=2.53, p=0.02)$, and lacking access to health care $(\mathrm{OR}=2.84, p<0.01)$. Even in cases where refugees are granted basic rights, their integration prospects are often limited and the effects of sexual and other types of violence on psychological distress are often compounded by the accumulation of post- 
Table 4 Association between PTSD score and sexual and non-sexual traumatic experiences

\begin{tabular}{|c|c|c|c|c|c|c|}
\hline \multirow[t]{2}{*}{ Type of violence } & \multicolumn{4}{|l|}{ PTSD } & \multicolumn{2}{|c|}{ Goodness of fit } \\
\hline & Unadjusted OR (95\% Cl) & $p$-value & Adjusted OR $(95 \% \mathrm{Cl})^{\mathrm{a}}$ & $p$-value & F-statistic & $p$-value \\
\hline \multicolumn{7}{|l|}{ Sexual violence } \\
\hline Rape & $2.24(1.2-4.18)$ & 0.01 & $2.43(1.27-4.65)$ & 0.01 & 0.70 & 0.71 \\
\hline Gang rape & $2.04(0.97-4.28)$ & 0.06 & $1.92(0.91-4.06)$ & 0.09 & 1.95 & 0.05 \\
\hline Pregnancy resulting from rape & $1.57(0.77-3.20)$ & 0.22 & $1.70(0.85-3.44)$ & 0.13 & 0.82 & 0.59 \\
\hline Rape before displacement & $0.79(0.40-1.57)$ & 0.50 & $0.90(0.45-1.81)$ & 0.77 & 2.14 & 0.02 \\
\hline Rape during flight & $0.93(0.47-1.85)$ & 0.84 & $0.86(0.67-0.43)$ & 1.73 & 0.89 & 0.53 \\
\hline Rape after displacement & $3.06(1.35-6.92)$ & $<0.001$ & $3.17(1.37-7.37)$ & $<0.001$ & 0.61 & 0.79 \\
\hline \multicolumn{7}{|l|}{ Non-sexual traumatic experiences } \\
\hline Lack of shelter & $3.02(1.52-5.99)$ & 0.00 & $2.86(1.43-5.74)$ & 0.00 & 1.01 & 0.43 \\
\hline Lack of food/water & $2.53(1.14-5.62)$ & 0.02 & $2.53(1.18-5.43)$ & 0.02 & 0.89 & 0.53 \\
\hline Lack of access to health care & $289(1.57-5.30)$ & 0.00 & $2.84(1.55-5.23)$ & 0.00 & 0.49 & 0.88 \\
\hline Destruction of property & $2.38(1.13-4.98)$ & 0.02 & $2.48(1.18-5.22)$ & 0.02 & 0.47 & 0.90 \\
\hline Sustained beatings & $1.91(1.03-3.53)$ & 0.04 & $1.87(1.01-3.49)$ & 0.05 & 1.53 & 0.13 \\
\hline Tortured & $1.61(0.92-2.82)$ & 0.10 & $1.71(0.97-3.03)$ & 0.06 & 0.74 & 0.67 \\
\hline War-related injury & $2.14(1.22-3.73)$ & 0.01 & $2.04(1.16-3.57)$ & 0.01 & 0.85 & 0.57 \\
\hline Imprisonment & $1.81(0.91-3.61)$ & 0.09 & $1.73(0.86-3.45)$ & 0.12 & 3.77 & $<0.001$ \\
\hline Forced labor & $2.77(1.50-5.12)$ & 0.00 & $2.60(1.39-4.85)$ & 0.00 & 0.48 & 0.89 \\
\hline Extortion, robbery & $3.28(1.75-6.14)$ & $<0.001$ & $3.08(1.61-5.89)$ & 0.00 & 2.99 & 0.002 \\
\hline Kidnapped & $1.66(0.96-2.88)$ & 0.07 & $1.65(0.94-2.87)$ & 0.08 & 0.77 & 0.65 \\
\hline Find and bury bodies & $2.12(1.07-4.20)$ & 0.03 & $2.20(1.10-4.37)$ & 0.03 & 0.64 & 0.76 \\
\hline Forced to betray family or friend, risking their lives & $4.70(1.08-2.46)$ & 0.04 & $4.46(1.04-19.06)$ & 0.04 & 2.12 & 0.03 \\
\hline Violent death of spouse or child & $1.82(0.95-3.51)$ & 0.07 & $1.73(0.89-3.36)$ & 0.10 & 0.80 & 0.61 \\
\hline Death of family/friend & $2.12(1.15-3.90)$ & 0.02 & $2.15(1.18-3.94)$ & 0.01 & 0.74 & 0.68 \\
\hline Disappearance of spouse/child & $1.94(1.12-3.38)$ & 0.02 & $1.90(1.09-3.31)$ & 0.02 & 2.49 & 0.008 \\
\hline Disappearance, kidnapping of family/friend & $2.44(1.37-4.33)$ & 0.00 & $2.72(1.54-4.82)$ & 0.00 & 2.75 & 0.004 \\
\hline Witnessed physical injury of family/friend in combat & $1.92(1.10-3.34)$ & 0.02 & $1.99(1.14-3.47)$ & 0.02 & 2.03 & 0.03 \\
\hline Witnessed beating/torture of other people & $1.83(0.99-3.38)$ & 0.06 & $1.82(0.98-3.38)$ & 0.06 & 1.52 & 0.14 \\
\hline Witnessed killing or murder of other people & $3.06(1.73-5.39)$ & $<0.001$ & $3.28(1.86-5.79)$ & $<0.00$ & 0.48 & 0.89 \\
\hline$<=10$ traumatic experiences & Ref. & & & & & \\
\hline Between 11 and 15 traumatic experiences & $1.20(1.12-1.29)$ & $<0.001$ & $1.21(1.12-1.29)$ & $<0.001$ & 0.77 & 0.64 \\
\hline$>15$ traumatic experiences & $2.11(1.39-3.19)$ & $<0.001$ & $2.15(1.42-3.24)$ & $<0.001$ & 0.81 & 0.61 \\
\hline
\end{tabular}

${ }^{a}$ Models were adjusted for age, social support and education level

migration stressors [23] and cultural adaptation [24]. In Burundi and Uganda, for example, DRC refugees have the legal right to work but employment rates are extremely low, limiting their access to livelihoods [25]. By identifying and evaluating post-migration stressors, services and programs in host countries can more effectively manage the critical psychosocial and general health needs of this population, facilitating positive adaptation within host communities.

Given the confined nature and restrictions associated with living in settlements, refugees around the world are increasingly opting to 'self-settle' in border areas of large urban hubs [2]. But the extent to which refugees can be agents of development is limited by local government policy allowing their integration. At the time of the survey in 2013, there were an estimated 48,000 Congolese living in Kampala [26], with the majority being recognized by the host Government on a prima facie basis [1] If provided with appropriate supportive services, including legal, healthcare and psychosocial support, and within a framework of local integration, urban settlements may prove to be better alternatives to camps and succeed where other models have failed [27]. In order to inform local settlement policy, more research with appropriate methodological approaches is needed to understand the current situation and livelihoods of self- 
Table 5 Association between depression and traumatic experiences

\begin{tabular}{|c|c|c|c|c|c|c|}
\hline \multirow[t]{2}{*}{ Type of violence } & \multicolumn{4}{|l|}{ Depression } & \multicolumn{2}{|c|}{ Goodness of fit } \\
\hline & Unadjusted OR (95\% Cl) & $p$-value & $\begin{array}{l}\text { Adjusted OR } \\
(95 \% \mathrm{CI})^{*}\end{array}$ & $p$-value & F-statistic & $p$-value \\
\hline \multicolumn{7}{|l|}{ Sexual violence } \\
\hline Rape & $2.41(1.28-4.53)$ & 0.01 & $2.30(1.21-4.38)$ & 0.01 & 1.57 & 0.12 \\
\hline Gang rape & $1.56(0.75-3.25)$ & 0.24 & $1.62(0.78-3.36)$ & 0.20 & & \\
\hline Pregnancy resulting from rape & $1.96(1.05-3.68)$ & 0.04 & $1.70(0.89-3.23)$ & 0.11 & 0.85 & 0.57 \\
\hline Rape before displacement & $1.28(0.71-2.27)$ & 0.41 & $1.21(0.67-2.18)$ & 0.52 & 1.89 & 0.05 \\
\hline Rape during flight & $0.90(0.50-1.63)$ & 0.73 & $1.03(0.57-1.88)$ & 0.91 & 1.96 & 0.04 \\
\hline Rape after displacement & $1.44(0.74-2.80)$ & 0.28 & $1.45(0.74-2.81)$ & 0.27 & 1.80 & 0.07 \\
\hline \multicolumn{7}{|l|}{ Non-sexual traumatic experiences } \\
\hline Lack of access to health care & $1.71(0.96-3.07)$ & 0.07 & $1.71(0.94-3.11)$ & 0.08 & 1.58 & 0.12 \\
\hline Destruction of property & $2.59(1.27-5.31)$ & 0.01 & $1.88(0.90-3.94)$ & 0.09 & 1.74 & 0.08 \\
\hline Forced labor & $1.58(0.95-2.62)$ & 0.08 & $1.72(1.01-2.94)$ & 0.05 & 0.85 & 0.57 \\
\hline Forced to betray family or friend, risking their lives & $2.30(0.91-5.82)$ & 0.08 & $2.43(0.98-5.99)$ & 0.05 & 1.96 & 0.04 \\
\hline Death of family/friend & $1.59(0.96-2.64)$ & 0.07 & $1.64(0.98-2.76)$ & 0.06 & 1.04 & 0.41 \\
\hline Disappearance, kidnapping of spouse /child & $2.13(1.28-3.53)$ & $<0.01$ & $1.99(1.16-3.40)$ & 0.01 & 2.25 & 0.02 \\
\hline$<=10$ traumatic experiences & Ref. & & & & & \\
\hline Between 11 and 15 traumatic experiences & $1.25(0.91-1.73)$ & 0.17 & $1.19(0.84-1.67)$ & 0.32 & 1.19 & 0.30 \\
\hline$>15$ traumatic experiences & $1.21(0.73-1.99)$ & 0.47 & $1.2-(0.71-2.02)$ & 0.49 & 1.55 & 0.13 \\
\hline
\end{tabular}

settled refugees. For example, qualitative interviews with self-settled Congolese refugees highlight the need for research on the role of social functioning to expand our understanding of social support seeking behaviors from family and community resources that can be harnessed as part of psychosocial interventions [28]. Finally, host countries should support international legal frameworks permitting the safe reporting and prosecution of systematic sexual violence, with sexual violence survivor programs and mental health services included as part of these efforts.

This paper should be viewed in light of a few limitations. We relied on self-reported measures that could introduce social-desirability bias. The survey included sensitive questions and it is possible that participants under-reported traumatic events, including rape. However, the use of ACASI might have helped diminish this as has been the case in other studies [29]. PTSD and depression were classified based on symptom criteria and diagnostic interviews were not conducted. Questions could have been misinterpreted or instruments may not match local constructs of disease. We also lacked measures to examine the access to and uptake of mental health services for this afflicted population in Kampala. Data were collected in 2013 and refugees' situation and needs may have changed since. However, many Congolese refugees remain in Kampala and given the large influx of additional Congolese refugees to Uganda in 2018 and ongoing [2], we anticipate that the need for psychosocial support given past exposure to trauma as shown here is very likely to remain.
Despite limitations, this paper has several significant strengths. First, this study provides data on mental health outcomes, traumatic experiences and rape among a population of women less represented in other research approaches. Many refugees prefer not to live in camps if they have the option and settle in urban environments but are less represented in the literature. Second, our sample was large and the use of RDS allowed us to generate population-based estimates among a hard to sample group. Third, ACASI interviewing allowed participants to privately answer sensitive and personal questions on a computer with headphones, increasing the likelihood of disclosing traumatic events, including rape.

\section{Conclusions}

In summary, our survey among DR Congolese female refugees self-settled in Kampala sheds light on the shocking frequency of violence, sexual and otherwise, that female refugees endure before, during and after flight, and the high rates of adverse mental health outcomes associated with it. Future programming addressing self-settled refugees should be designed to include services responding to high levels of rape and associated PTSD, as well as ongoing vulnerability to rape in the country of asylum, if they are to succeed.

\section{Abbreviations}

ACASI: Audio computer-assisted self-interview; CDC: Centers for Disease Control and Prevention; Cl: Confidence Interval; DRC: Democratic Republic of Congo; HTQ: Harvard Trauma Questionnaire; HIV: Human Immunodeficiency 
Virus; MSPSS: Multidimensional Scale of Perceived Social Support; NGO: Nongovernmental organizations; OR: Odds Ratio; PHQ: Patient Health Questionnaire; PTSD: Post-traumatic stress disorder; RDS: Respondent-driven sampling; UNHCR: UN High Commissioner for Refugees

\section{Acknowledgments}

We thank the survey respondents for their participation.

\section{Authors' contributions}

All authors substantially contributed to the study's design, conduct, or to data analysis and interpretation, wrote or edited parts of the manuscript, and approved the final version for publication.

\section{Funding}

This project has been supported by the President's Emergency Plan for AIDS Relief (PEPFAR) through the Centers for Disease Control and Prevention under the terms of cooperative agreement 5U2GPS000971.

\section{Availability of data and materials}

The datasets generated and/or analyzed during the current study are not publicly available for ethical reasons but are available from the corresponding author upon reasonable request.

\section{Declarations}

\section{Ethics approval and consent to participate}

All participants provided oral informed consent for their participation in the survey and testing. The survey protocol was approved by the ethics committee of Makerere University's School of Public Health and the Uganda National Council of Science and Technology and was reviewed by CDC's Associate Director of Science.

\section{Consent for publication}

Not applicable.

\section{Competing interests}

The corresponding authors had full access to all study data and final responsibility for the decision to submit this manuscript for publication. All authors declare that they have no conflicts of interest.

\section{Author details}

${ }^{1}$ Department of Psychiatry, Michigan State University, East Lansing, MI, USA. ${ }^{2}$ Division of Global HIV and TB, Centers for Disease Control and Prevention, Kampala, Uganda. ${ }^{3}$ Refugee Law Project, School of Law, Makerere University, Kampala, Uganda. ${ }^{4}$ School of Public Health, Makerere University, Kampala, Uganda. ${ }^{5}$ Department of Disease Control, School of Public Health, Makerere University, Kampala, Uganda. ${ }^{6}$ Action Marguerite, Winnipeg, Manitoba, Canada. 'Division of Global HIV and TB, Centers for Disease Control and Prevention, MS E-30, 1600 Clifton Rd, Atlanta GA-30333, USA.

Received: 21 January 2021 Accepted: 11 May 2021 Published online: 26 May 2021

\section{References}

1. UNHCR. Resettlement statistical report. Geneva: UNCHR; 2013.

2. United Nations Human Rights. Office of the High Commissioner for Human R. UNHCR Global Trends 2018. Geneva: UNHCR; 2018.

3. Ohambe MC, Galloy MR, Sow N. Women's bodies as a battleground: sexual violence against women and girls during the war in the Democratic Republic of Congo: South Kivu (1996-2003); 2004.

4. Siriwardhana C, Ali SS, Roberts B, Stewart R. A systematic review of resilience and mental health outcomes of conflict-driven adult forced migrants. Confl Heal. 2014;8(1):13. https://doi.org/10.1186/1752-1505-8-13.

5. Hameed S, Sadiq A, Din AU. The increased vulnerability of refugee population to mental health disorders. Kans J Med. 2018;11(1):20.

6. Vu A, Adam A, Wirtz A, Pham K, Rubenstein L, Glass N, et al. The prevalence of sexual violence among female refugees in complex humanitarian emergencies: a systematic review and meta-analysis. PLoS Curr. 2014,6:ecurrents.dis. 835f10778fd80ae031aac12d3b533ca7.

7. Johnson K, Scott J, Rughita B, Kisielewski M, Asher J, Ong R, et al. Association of sexual violence and human rights violations with physical and mental health in territories of the eastern Democratic Republic of the Congo. Jama. 2010;304(5):553-62. https://doi.org/10.1001/jama.2010.1086.

8. Peterman A, Palermo T, Bredenkamp C. Estimates and determinants of sexual violence against women in the Democratic Republic of Congo. Am J Public Health. 2011;101(6):1060-7. https://doi.org/10.2105/AJPH.2010.300070.

9. Ainamani HE, Elbert T, Olema DK, Hecker T. PTSD symptom severity relates to cognitive and psycho-social dysfunctioning - a study with Congolese refugees in Uganda. Eur J Psychotraumatol. 2017;8(1):1283086. https://doi. org/10.1080/20008198.2017.1283086.

10. Morof DF, Sami S, Mangeni M, Blanton C, Cardozo BL, Tomczyk B. A crosssectional survey on gender-based violence and mental health among female urban refugees and asylum seekers in Kampala, Uganda. Int J Gynecol Obstet. 2014;127(2):138-43. https://doi.org/10.1016/j.ijgo.2014.05.014.

11. Kroenke K, Spitzer RL, Williams JBW. The patient health Questionnaire-2: validity of a two-item depression screener. Med Care. 2003;41(11):1284-92. https://doi.org/10.1097/01.MLR.0000093487.78664.3C.

12. Mollica RF, Caspi-Yavin Y, Bollini P, Truong T, Tor S, Lavelle J. The Harvard trauma questionnaire: validating a cross-cultural instrument for measuring torture, trauma, and posttraumatic stress disorder in Indochinese refugees. J Nerv Ment Dis. 1992; 180(2):111-6.

13. Zimet GD, Dahlem NW, Zimet SG, Farley GK. The multidimensional scale of perceived social support. J Pers Assess. 1988:52(1):30-41.

14. Handcock MS, Fellows IE, Gile KJ. RDS analyst: software for the analysis of respondent-driven sampling data, Version 0.42. Los Angeles: Hard to Reach Population Methods Research Group; 2014.

15. College Station TXSLP. Stata statistical software: Release 11. 2010.

16. Tomczyk B, Goldberg H, Blanton C, Gakuba R, Saydee G, Warwah P. Women's reproductive health in Liberia: the Lofa County reproductive health survey. Atlanta: CDC; 2007

17. Kelly J, Albutt K, Kabanga J, Anderson K, VanRooyen M. Rejection, acceptance and the spectrum between: understanding male attitudes and experiences towards conflict-related sexual violence in eastern Democratic Republic of Congo. BMC Womens Health. 2017:17(1):127. https://doi.org/10.1186/s12905-017-0479-7.

18. Abu Suhaiban $H$, Grasser LR, Javanbakht A. Mental health of refugees and torture survivors: a critical review of prevalence, predictors, and integrated care. Int J Environ Res Public Health. 2019;16(13):2309.

19. Scott J, Rouhani S, Greiner A, Albutt K, Kuwert P, Hacker MR, et al. Respondent-driven sampling to assess mental health outcomes, stigma and acceptance among women raising children born from sexual violencerelated pregnancies in eastern Democratic Republic of Congo. BMJ Open. 2015;5(4):e007057. https://doi.org/10.1136/bmjopen-2014-007057.

20. Cardozo BL, Bilukha OO, Gotway CA, Wolfe Ml, Gerber ML, Anderson M. Report from the CDC: mental health of women in postwar Afghanistan. J Womens Health (2002). 2005;14(4):285-93.

21. Burgess AW, Holmstrom LL. Rape trauma syndrome. Am J Psychiatr. 1974;131(9):981-6.

22. McGowan MG, Helms JL. The utility of the expert witness in a rape case: reconsidering rape trauma syndrome. J Forensic Psychol Pract. 2003;3(1):5160. https://doi.org/10.1300/J158v03n01_05.

23. Hou WK, Liu H, Liang L, Ho J, Kim H, Seong E, et al. Everyday life experiences and mental health among conflict-affected forced migrants: a meta-analysis. J Affect Disord. 2020;1(264):50-68.

24. Mollica RF, Cardozo BL, Osofsky HJ, Raphael B, Ager A, Salama P. Mental health in complex emergencies. Lancet. 2004;364(9450):2058-67. https://doi. org/10.1016/S0140-6736(04)17519-3.

25. Europe ICMCI. Welcome to Europe! A Guide to Resettlement. Brussels: ICMC; 2013.

26. Centers for Disease Control and Prevention. Congolese refugee health profile. 2016. https://www.cdc.gov/immigrantrefugeehealth/profiles/ congolese/index.html. Accessed on: 22/05/2021.

27. Hovil L. Self-settled refugees in Uganda: an alternative approach to displacement? J Refug Stud. 2007;20(4):599-620.

28. Chiumento A, Rutayisire T, Sarabwe E, Hasan MT, Kasujja R, Nabirinde R, et al. Exploring the mental health and psychosocial problems of Congolese refugees living in refugee settings in Rwanda and Uganda: a rapid qualitative study. Confl Heal. 2020;14(1):1-21.

29. Cooley PC, Miller HG, Gribble JN, Turner CF. Automating telephone surveys: using T-ACASI to obtain data on sensitive topics. Comput Hum Behav. 2000; 16(1):1-11. https://doi.org/10.1016/S0747-5632(99)00048-5.

\section{Publisher's Note}

Springer Nature remains neutral with regard to jurisdictional claims in published maps and institutional affiliations. 